\title{
Understanding the adoption and use of point-of-care tests in Dutch general practices using multi-criteria decision analysis
}

Michelle M. A. Kip ${ }^{1 *}$ D, J. Marjan Hummel ${ }^{1}$, Elra B. Eppink ${ }^{1}$, Hendrik Koffijberg ${ }^{1}$, Rogier M. Hopstaken², Maarten J. IJzerman ${ }^{1}$ and Ron Kusters ${ }^{1,3}$

\begin{abstract}
Background: The increasing number of available point-of-care (POC) tests challenges clinicians regarding decisions on which tests to use, how to efficiently use them, and how to interpret the results. Although POC tests may offer benefits in terms of low turn-around-time, improved patient's satisfaction, and health outcomes, only few are actually used in clinical practice. Therefore, this study aims to identify which criteria are, in general, important in the decision to implement a POC test, and to determine their weight. Two POC tests available for use in Dutch general practices (i.e. the C-reactive protein (CRP) test and the glycated haemoglobin ( $\mathrm{HbA}_{1 c}$ ) test) serve as case studies. The information obtained from this study can be used to guide POC test development and their introduction in clinical practice.
\end{abstract}

Methods: Relevant criteria were identified based on a literature review and semi-structured interviews with twelve experts in the field. Subsequently, the criteria were clustered in four groups (i.e. user, organization, clinical value, and socio-political context) and the relative importance of each criterion was determined by calculating geometric means as implemented in the Analytic Hierarchy Process. Of these twelve experts, ten participated in a facilitated group session, in which their priorities regarding both POC tests (compared to central laboratory testing) were elicited.

Results: Of 20 criteria in four clusters, the test's clinical utility, its technical performance, and risks (associated with the treatment decision based on the test result) were considered most important for using a POC test, with relative weights of 22.2, 12.6 and $8.5 \%$, respectively. Overall, the experts preferred the POC CRP test over its laboratory equivalent, whereas they did not prefer the POC $\mathrm{HbA}_{1 c}$ test. This difference was mainly explained by their strong preference for the POC CRP test with regard to the subcriterion 'clinical utility'.

Conclusions: The list of identified criteria, and the insights in their relative impact on successful implementation of POC tests, may facilitate implementation and use of existing POC tests in clinical practice. In addition, having experts score new POC tests on these criteria, provides developers with specific recommendations on how to increase the probability of successful implementation and use.

Keywords: Analytic hierarchy process, Health technology assessment, Adoption, Multi-criteria decision analysis, Pointof-care tests, Preference elicitation, Primary care

\footnotetext{
* Correspondence: m.m.a.kip@utwente.nl

'Department of Health Technology and Services Research, Faculty of

Behavioural, Management and Social Sciences, Technical Medical Centre,

University of Twente, P.O. Box 217, 7500, AE, Enschede, The Netherlands

Full list of author information is available at the end of the article
}

(c) The Author(s). 2019 Open Access This article is distributed under the terms of the Creative Commons Attribution 4.0 International License (http://creativecommons.org/licenses/by/4.0/), which permits unrestricted use, distribution, and reproduction in any medium, provided you give appropriate credit to the original author(s) and the source, provide a link to the Creative Commons license, and indicate if changes were made. The Creative Commons Public Domain Dedication waiver (http://creativecommons.org/publicdomain/zero/1.0/) applies to the data made available in this article, unless otherwise stated. 


\section{Background}

In the last decades, the use of diagnostic tests has increased rapidly. This number is expected to rise even further given the increasing number of people with multiple (chronic) conditions, and the availability of a wide range of biomarkers for monitoring disease and treatment response [1, 2]. Rapid, accurate diagnostic tests have the potential to improve targeted treatments or referrals and thereby improve the overall quality and efficiency of care delivery. However, the availability of new diagnostic tests also challenges physicians to effectively use and interpret the (combination of) test results [3]. This particularly applies to general practitioners (GPs), as they encounter a wide variety of medical conditions among patients presenting in their general practice, and have to decide on whether or not (and which) diagnostic test(s), if any, to perform in those patients. Although most of the laboratory tests requested by GPs are still performed in central laboratories, advances in technology increasingly allow to perform some of these tests directly during consultation, i.e. at the point-of-care [4], offering large benefits in terms of timely and targeted treatment [5].

More specifically, POC tests have been shown to improve patient's satisfaction, treatment adherence, and health outcomes, while also saving time and costs $[4,6-$ 10]. In addition, previous research indicated that GPs express the desire to have POC tests available to help them diagnose a range of acute and chronic conditions [11]. Despite these clear advantages, only a limited number of POC tests are actually used in clinical practice $[11,12]$. Reasons for non-use include concerns about test accuracy, over-reliance on test results, undermining clinical judgment, limited added value on top of clinical judgement, as well as higher average costs of POC testing compared to central laboratory testing, and test reimbursement $[12,13]$.

The decision to actually implement a POC test instead of continuing to request central laboratory tests is a tradeoff between multiple, often conflicting, objectives [1416]. The use of structured, explicit approaches to decision-making involving multiple criteria can improve the quality of decisions and identify factors for improvement [16]. A set of techniques known as multiple criteria decision analysis (MCDA) can be used for this purpose [16]. In health technology assessment, MCDA can be used to obtain clarity on the relevance of decision criteria, and on the performance of alternative technologies (e.g. diagnostic tests) on these criteria, thereby increasing the consistency, transparency, and legitimacy of ensuing implementation decisions [16]. One of the most frequently applied techniques for MCDA, which is often applied in group decision making, is the analytic hierarchy process (AHP) $[17,18]$. In AHP, complex decision problems are reduced to multiple pairwise comparisons, and captures both subjective and objective criteria in the decision-making process [17]. Besides its application in healthcare, AHP has been applied to a large variety of other decision problems, ranging from decision problems in industry and politics to the composition of sports teams [19].

The current study uses AHP to estimate the relative preference for a POC test as compared to the same test when performed in a central laboratory. This will give insights in the criteria which are considered most important in the decision on whether or not to implement and use a POC test. We selected two cases that impact care delivery yet face implementation difficulty, i.e. the POC C-reactive protein (CRP) test, and the POC glycosylated haemoglobin $\left(\mathrm{HbA}_{1 \mathrm{c}}\right)$ test. CRP is an acute-phase protein measured in a patient's blood enabling the physician to differentiate between patients with bronchitis from those with community-acquired pneumonia. Use of the POC tests allows GPs to immediately decide whether or not antibiotic treatment is required [10, 20-24], and was used by $80 \%$ of Dutch GPs in 2015 [25].

The $\mathrm{HbA}_{1 \mathrm{c}}$ test is used to regularly monitor diabetes patients. Those patients typically have to visit a nurse or phlebotomist for a venipuncture, 1-2 weeks prior to their appointment [26]. A POC $\mathrm{HbA}_{1 \mathrm{c}}$ blood test offers immediate test results, thereby allowing immediate therapeutic decision making, and consequently, reducing patient visits for phlebotomies [26, 27]. In 2015, the POC $\mathrm{HbA}_{1 \mathrm{c}}$ test was used by $19 \%$ of Dutch GPs [25].

Although the abovementioned examples indicate the potential added value of both POC tests, they differ strongly in their degree of implementation. Therefore, these tests were selected as case studies to get insight into the relative preference of experts regarding the use of POC tests in primary care. This preference is estimated using AHP, by identifying and weighting the criteria that are relevant to the decision to use the POC test. Thereby, this study aims to determine which criteria are, in general, important in the decision to implement and use a POC test in clinical practice. This information is highly relevant to all stakeholders involved in the process of developing, evaluating and implementing POC tests in clinical practice.

\section{Methods}

Multi-criteria decision analysis with the analytic hierarchy process

The implementation of an MCDA study follows several separate steps [18], and guidance is provided by the taskforce of the International Society For Pharmacoeconomics and Outcomes Research [28]. Firstly, the framework for the analysis is determined by setting the goal of the analysis, identifying the alternatives that are compared (i.e. POC CRP and POC $\mathrm{HbA}_{1 \mathrm{c}}$ as alternatives 
to their equivalent central laboratory tests), and defining the relevant criteria. Secondly, importance weights are obtained for each of the criteria. Thirdly, the performance of both POC tests on each decision criterion was valued relatively to the performance of their laboratory equivalents. The final step is the aggregation of the scores and weights to determine the relative value for the POC CRP and the POC $\mathrm{HbA}_{1 \mathrm{c}}$ test, as alternative to their equivalent central laboratory test. An overview of these steps, which will be referred to in the remainder of the methods section, is provided in Fig. 1. We assume that the technique with the highest value is the preferred one, and is therefore most likely to be implemented (and used) in clinical practice.

\section{Problem structuring}

\section{Defining the decision problem and goal \& identification of} the alternatives (steps 1 \& 2)

For this AHP, it is assumed that the use of a POC CRP test or a POC $\mathrm{HbA}_{1 \mathrm{c}}$ test will replace the use of the equivalent test performed in a central laboratory, instead of being used as an additional test in the diagnostic track. This means that the criteria regarding the (potential) use of a

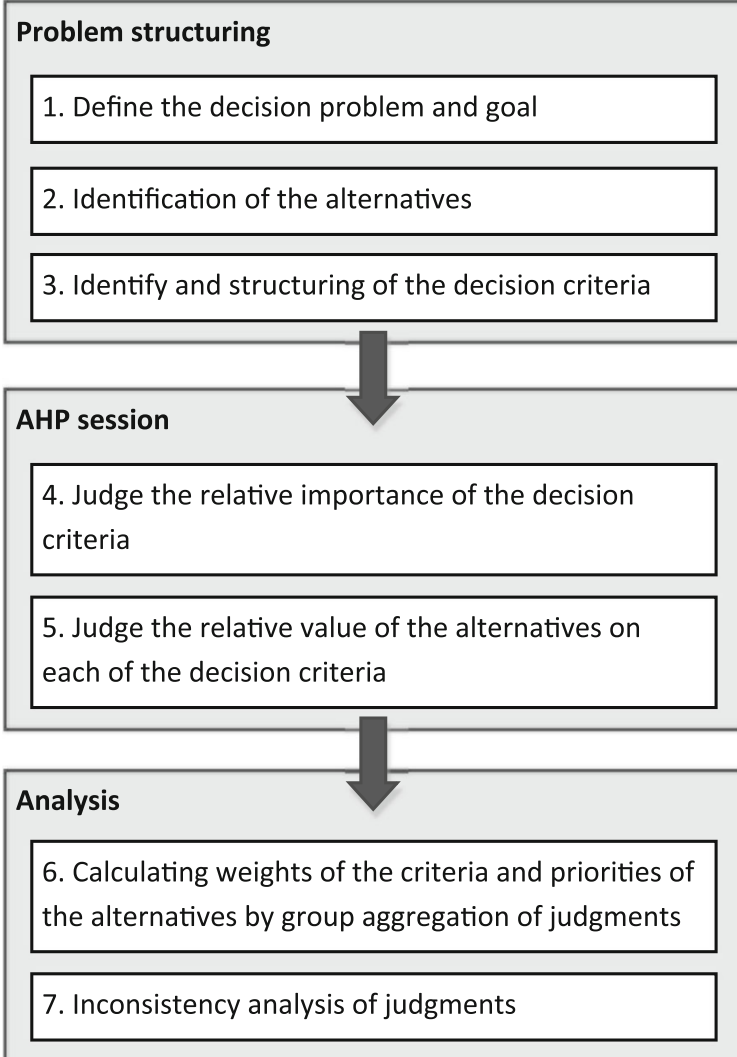

Fig. 1 Steps in the AHP. This figure shows an overview of the different steps that are performed in the analytical hierarchy process (AHP)
POC test within the GP's office will be compared to the criteria of the equivalent test when performed in a central laboratory (step 1) based on two case studies (i.e. CRP and $\mathrm{HbA}_{1 \mathrm{c}}$ ) (step 2).

Besides the difference in the degree of diffusion of the POC CRP and the POC $\mathrm{HbA}_{1 \mathrm{c}}$ test (as mentioned in the introduction), both cases have very different areas of application, thereby increasing the probability that the results obtained from this AHP are also relevant to the wide range of POC tests that can be used in Dutch general practices.

\section{Identification and structuring of the decision criteria (step 3)}

Relevant criteria for the AHP analysis were identified from a literature search, of which the details are described in Additional file 1. The literature search resulted in the inclusion of 7 journal articles, 1 guideline, and 3 reports [9, 11, 12, 29-36]. Each paper was independently assessed by two reviewers (EE and $\mathrm{MK}$ ) to identify all relevant criteria. The criteria obtained were compared to a previously published study in implementation science [37]. As this previous study specifically focused on guidelines and intervention programs in healthcare [37], the criteria identified from the current literature search differed from those reported in this previous study. However, this previous study categorized all criteria into four groups of main criteria, which are: 1) the user, 2) the organization, 3) the clinical value, and 4) the socio-political context [37]. As these generic groups are considered applicable to all kind of health-related interventions, this categorization of criteria was used for the purpose of the current study. Both the identification of the criteria, as well as categorizing those criteria into the four main groups of criteria were performed by the same two reviewers (EE and MK). Differences were discussed until consensus was reached.

Expert panel In order to judge both the validity and completeness of this list of criteria, the (potential) presence of redundant or overlapping criteria, as well as the preferential independence of the criteria [28], the initial list and suggested structure were validated by means of individual interviews with 12 experts. In addition, these experts also judged the clarity, completeness, and unambiguity of the definitions accompanying each of the criteria. The panel of experts was selected in such a way to represent all stakeholders who are either involved in the process of POC test development, or its implementation and use in clinical practice. A full overview of the participating experts and their professional backgrounds is presented in Table 1. All participating experts were informed on the goal of the study as well as on the duration of the interview and the AHP session. As the 
Table 1 Composition of expert team

\begin{tabular}{|c|c|c|}
\hline No. & Profession & Core relation to POC testing in general practices \\
\hline 1 & GP & User of $\mathrm{CRP}$ and $\mathrm{HbA}_{1 \mathrm{c}}$ test \\
\hline 2 & GP & User of CRP test, non-user $\mathrm{HbA}_{1 \mathrm{c}}$ test \\
\hline 3 & GP & User of CRP test, non-user $\mathrm{HbA}_{1 c}$ test \\
\hline 4 & GP's assistant & User of CRP test, non-user $\mathrm{HbA}_{1 c}$ test, former nurse \\
\hline 5 & Diabetic patient & User of $\mathrm{HbA}_{1 \mathrm{c}}$ test (as a patient), biology teacher (familiar with CRP) \\
\hline 6 & Clinical chemist & Laboratory professional, specialized in POC tests in primary care \\
\hline $7^{b}$ & Clinical chemist & Laboratory professional, specialized in POC tests in primary care \\
\hline 8 & Technology developer & Director lab-on-a-chip company \\
\hline 9 & Policy maker & Concerned with the quality of care provided in primary care \\
\hline $10^{\mathrm{a}}$ & POC specialist & Expert in POC testing, GP \\
\hline $11^{\mathrm{a}}$ & Payer & Insurer in primary health care, former GP \\
\hline $12^{\mathrm{b}}$ & Payer & Former director of health insurance company, and professor in healthcare \\
\hline
\end{tabular}

${ }^{a}$ did not participate in the group AHP session but completed the AHP session afterwards. ${ }^{b}$ did not participate in the AHP session. CRP $=C$-reactive protein, GP $=$ general practitioner, $H b A_{1 c}=$ glycated haemoglobin, $P O C=$ point-of-care

current study focused on the Dutch setting, all selected participants were living and employed in the Netherlands. The participants were initially approached via email. Participation was voluntary and the experts had the opportunity to quit participation at any time. This study was approved by the Ethics Committee of the faculty Behavioural, Management and Social Sciences of the University of Twente, Enschede, the Netherlands.

Validation of the list of criteria obtained from literature was performed by means of individual, semi-structured interviews with each of the 12 experts (by EE), either via phone or at the expert's workplace. After each session, the suggested adaptations to the identification and structuring of the criteria, were discussed by MK and EE until consensus was reached. The updated list was then used as input for the next semi-structured interview. This repetitive process resulted in a final list of 20 criteria (categorized in four groups of five subcriteria), which were expected to affect the implementation and use of POC tests in general practices. These criteria were used to compose the hierarchical evaluation structure (Fig. 2). A full description of the 20 subcriteria, and the accompanying range applied in the AHP session, is included in Additional file 2 (step 3).
All 12 experts who participated in the initial interviews (Table 1), were also invited to participate in the AHP session (at the University of Twente). A group setting was chosen for this AHP because it allows panel members to share information about their attitudes, beliefs, as well as knowledge, which underlie the priorities they assign to the outcome measures [38]. One clinical chemist (expert no. 7) and the former director of a health insurance company (expert no. 12) were however unable to participate in the AHP session. All remaining ten experts agreed to participate in the AHP session, although two of those experts (expert no. 10 and expert no. 11) were unable to attend the actual group session, and therefore completed the AHP session individually afterwards.

\section{AHP session (steps 4 \& 5)}

The AHP session was performed in accordance with previously published literature and/or guidance documents [18, 39]. A three-hour AHP session was organized (by EE, and with attendance of $\mathrm{JH}$ and $\mathrm{MK}$ ) during which the expert team discussed the relative importance of the four main criteria as well as each of the five (sub) criteria within each main criterion. This session was performed using Team

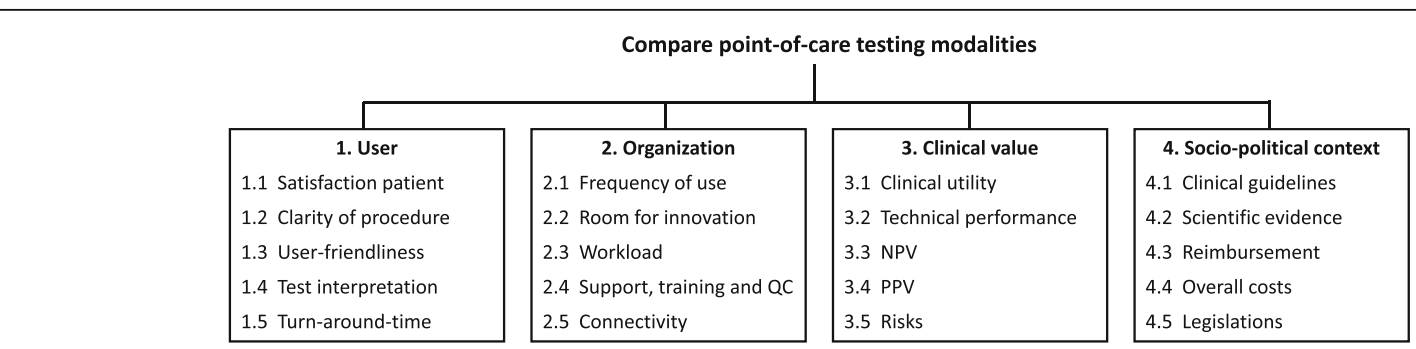

Fig. 2 Hierarchical structure of the AHP. This figure shows an overview of the hierarchical structured used for the analytical hierarchy process $(\mathrm{AHP}) . \mathrm{NPV}=$ negative predictive value, $\mathrm{POC}=$ point-of-care, $\mathrm{PPV}=$ positive predictive value, $\mathrm{QC}=$ quality control 
Expert Choice software (Expert Choice, Arlington, VA), a group decision support system which incorporates the mathematical procedures of AHP, and all conversations during this AHP session were audio recorded.

During this session, all members of the expert team were asked to provide their judgments on pairwise comparisons of the importance of the four main criteria, as well as the four groups of five subcriteria (step 4). In this step, the relative importance of the main criteria are judged using a nine-point rating scale. Criteria that are judged as equally important will receive a score of ' 1 '. If one of the criteria is judged more important than the other, the more important criterion will receive a score between 2 (equally to moderately more important), and 9 (extremely more important) [18]. Subsequently, the importance of each pair of subcriteria (stemming from the main criterion) is compared. Likewise, the preferences for the selected alternatives (i.e. for POC CRP vs. central laboratory CRP, and for POC $\mathrm{HbA}_{1 \mathrm{c}}$ vs. central laboratory $\mathrm{HbA}_{1 \mathrm{c}}$ ) with regard to the 20 criteria, is determined on similar nine-point scales (step 5). The performance of both POC tests and the central laboratory tests on the selected criteria was left to the experts' judgement. Responses were collected individually using hand-held remote controlled keypads. All individual judgments were projected on a screen, allowing the expert team members to provide their motivation for their individual scores, and to share their expertise on this topic. To allow the other team members to incorporate the expertise and motivations that were shared, they had the opportunity to alter their judgements during those dialogs. A detailed overview of the AHP session, and the pairwise-comparisons made, is provided in Additional file 2.

\section{Analysis (steps $6 \&$ 7)}

For each pairwise comparison, the final individual judgments were aggregated, based on the geometric mean. This resulted in group weighing factors which represented the relative importance of each of the criteria, and these weighing factors were used to calculate the relative preference for the alternatives (i.e., the POC test or the central laboratory test) (step 6). In addition, the inconsistency of the expert's judgments was calculated after the pair-wise comparisons of each of the main criteria, and after each of the 20 subcriteria. In accordance with literature, an inconsistency below 0.1 was considered acceptable [17]. In case of a too high inconsistency, the experts were asked to reconsider the pair-wise comparison which caused this inconsistency (to make sure that the criteria compared were well-understood), or they were asked to fill in an additional comparison (step 7).

\section{Results}

The results of the pairwise comparisons of the four main criteria and the 20 subcriteria, as well as the preferences regarding the POC CRP and POC $\mathrm{HbA}_{1 \mathrm{c}}$ test (as compared to their laboratory equivalents) are shown in Table 2.

Table 2 indicates that a change in the main criterion 'clinical value', as caused by the use of a POC test, is estimated to be most important for comparing preferences for a POC test with its central laboratory test. The other main criteria in order of decreasing importance are 'organisation', 'socio-political context' and 'user'. An overall group inconsistency within those four main criteria of 0.05 was found, which is acceptable considering the 0.1 threshold (Additional file 3).

Among the 20 subcriteria, the results indicate that the subcriterion 'clinical utility' is expected to have the highest impact on the relative preference for the POC test as compared to the central laboratory test (relative impact $22.2 \%)$, followed by 'technical performance' (12.6\%), and 'risks' (8.5\%). The high weights of those three subcriteria can also be explained by the high weight of the main criterion 'clinical value' (51.8\%), to which those three subcriteria belong. The subcriteria 'legislations,' 'connectivity', and 'test interpretation' were however found to have very little impact. The results of the comparison of the preferences of using the POC CRP test and the POC $\mathrm{HbA}_{1 \mathrm{c}}$ test as compared to using the equivalent central laboratory tests, are shown in Figs. 3 and 4, respectively.

Results indicate that the experts strongly prefer the POC CRP test as compared to its central laboratory test over all four main criteria, resulting in an overall preference of $62.9 \%$ vs. $37.1 \%$. The top four subcriteria that determined this preference involved the expected shorter 'turn-around time', an expected increase in 'patient satisfaction', the 'room for innovation' that is experienced, and its expected improvement in 'clinical utility' (Table 2 and Additional file 3).

However, the overall preference for the POC CRP test (over its central laboratory test) is dependent on the weights assigned to each of the subcriteria. Results indicate that the subcriteria 'clinical utility', and 'room for innovation' are most influential in favoring the POC test, whereas the subcriterion 'technical performance' was most influential in favoring the laboratory test.

In contrast, for the $\mathrm{HbA}_{1 \mathrm{c}}$ test, the experts displayed (almost) equal preference for the POC and the central laboratory test (i.e. $49.4 \%$ vs. $50.6 \%$ ). More specifically, with regard to the groups of main criteria, the POC test is only preferred over its central laboratory test for the main criterion 'user', caused by the preference for the POC $\mathrm{HbA}_{1 \mathrm{c}}$ test with regard to the subcriteria 'satisfaction patient,' 'user-friendliness', and 'turn-around-time' (Table 2 and Additional file 3). When taking into account the weight of the subcriteria, the subcriterion 'room for innovation' was found to be most influential in favor of POC $\mathrm{HbA}_{1 \mathrm{c}}$. However, in terms of 'clinical 
Table 2 Result of pairwise comparisons

\begin{tabular}{|c|c|c|c|c|c|c|c|}
\hline \multicolumn{2}{|c|}{ Determinant } & \multicolumn{2}{|l|}{ Weights* } & \multicolumn{4}{|c|}{ Performance scores } \\
\hline & & \multirow{2}{*}{$\begin{array}{l}\text { Weight of criterion } \\
13.6 \%\end{array}$} & \multirow{2}{*}{$\begin{array}{l}\text { Overall weight } \\
\text { NA }\end{array}$} & \multirow{2}{*}{$\begin{array}{l}\text { POC CRP } \\
81.9 \%\end{array}$} & \multirow{2}{*}{$\begin{array}{l}\text { CRP central lab } \\
18.1 \%\end{array}$} & \multirow{2}{*}{$\frac{\mathrm{POC} \mathrm{HbA}_{1 c}}{68.2 \%}$} & \multirow{2}{*}{$\frac{\mathrm{HbA}_{1 c} \text { central lab }}{31.8 \%}$} \\
\hline & ants in relation to the user & & & & & & \\
\hline 1 & Satisfaction patient & $25.4 \%$ & $3.5 \%$ & $89.9 \%$ & $10.1 \%$ & $85.3 \%$ & $14.7 \%$ \\
\hline 2 & Clarity of procedure & $24.8 \%$ & $3.4 \%$ & $71.3 \%$ & $28.7 \%$ & $56.1 \%$ & $43.9 \%$ \\
\hline 3 & User-friendliness & $21.0 \%$ & $2.9 \%$ & $84.2 \%$ & $15.8 \%$ & $78.1 \%$ & $21.9 \%$ \\
\hline 4 & Test interpretation & $6.4 \%$ & $0.9 \%$ & $69.0 \%$ & $31.0 \%$ & $50.0 \%$ & $50.0 \%$ \\
\hline 5 & Turn-around-time & $22.3 \%$ & $3.0 \%$ & $90.0 \%$ & $10.0 \%$ & $89.8 \%$ & $10.2 \%$ \\
\hline \multicolumn{2}{|c|}{ Determinants in relation to the organisation } & $20.9 \%$ & NA & $65.4 \%$ & $34.6 \%$ & $48.8 \%$ & $51.2 \%$ \\
\hline 6 & Frequency of use & $14.6 \%$ & $3.1 \%$ & $88.6 \%$ & $11.4 \%$ & $49.5 \%$ & $50.5 \%$ \\
\hline 7 & Room for innovation & $33.5 \%$ & $7.0 \%$ & $89.7 \%$ & $10.3 \%$ & $85.0 \%$ & $15.0 \%$ \\
\hline 8 & Workload & $22.1 \%$ & $4.6 \%$ & $77.1 \%$ & $22.9 \%$ & $29.6 \%$ & $70.4 \%$ \\
\hline 9 & Support, training and quality control & $25.4 \%$ & $5.3 \%$ & $21.3 \%$ & $78.7 \%$ & $24.4 \%$ & $75.6 \%$ \\
\hline 10 & Connectivity & $4.4 \%$ & $0.9 \%$ & $35.7 \%$ & $64.3 \%$ & $46.5 \%$ & $53.5 \%$ \\
\hline \multicolumn{2}{|c|}{ Determinants in relation to the clinical value } & $51.8 \%$ & NA & $55.1 \%$ & $44.9 \%$ & $45.8 \%$ & $54.2 \%$ \\
\hline 11 & Clinical utility & $42.8 \%$ & $22.2 \%$ & $89.4 \%$ & $10.6 \%$ & $53.5 \%$ & $46.5 \%$ \\
\hline 12 & Technical performance & $24.4 \%$ & $12.6 \%$ & $28.1 \%$ & $71.9 \%$ & $33.5 \%$ & $66.5 \%$ \\
\hline 13 & Negative Predictive Value & $13.7 \%$ & $7.1 \%$ & $48.3 \%$ & $51.7 \%$ & $50.0 \%$ & $50.0 \%$ \\
\hline 14 & Positive Predictive Value & $2.8 \%$ & $1.5 \%$ & $48.3 \%$ & $51.7 \%$ & $50.0 \%$ & $50.0 \%$ \\
\hline 15 & Risks & $16.4 \%$ & $8.5 \%$ & $34.4 \%$ & $65.6 \%$ & $33.5 \%$ & $66.5 \%$ \\
\hline \multicolumn{2}{|c|}{$\begin{array}{l}\text { Determinants in relation to the socio-political } \\
\text { context }\end{array}$} & $13.8 \%$ & NA & $72.9 \%$ & $27.1 \%$ & $49.1 \%$ & $50.9 \%$ \\
\hline 16 & Clinical guidelines & $34.1 \%$ & $4.7 \%$ & $82.1 \%$ & $17.9 \%$ & $47.3 \%$ & $52.7 \%$ \\
\hline 17 & Scientific evidence & $23.7 \%$ & $3.3 \%$ & $85.0 \%$ & $15.0 \%$ & $60.5 \%$ & $39.5 \%$ \\
\hline 18 & Reimbursement & $28.5 \%$ & $3.9 \%$ & $60.7 \%$ & $39.3 \%$ & $42.2 \%$ & $57.8 \%$ \\
\hline 19 & Overall costs & $8.3 \%$ & $1.1 \%$ & $88.8 \%$ & $11.2 \%$ & $55.5 \%$ & $44.5 \%$ \\
\hline 20 & Legislations & $5.5 \%$ & $0.8 \%$ & $42.3 \%$ & $57.7 \%$ & $40.5 \%$ & $59.5 \%$ \\
\hline \multicolumn{2}{|c|}{ Overall preference for POC or central laboratory test } & & & $62.9 \%$ & $37.1 \%$ & $49.4 \%$ & $50.6 \%$ \\
\hline
\end{tabular}

This table shows the results of the pairwise comparisons of the four main criteria and the 20 subcriteria, as well as the preferences regarding the POC CRP and $\mathrm{POC} \mathrm{HbA}_{1 \mathrm{c}}$ test (as compared to their central laboratory equivalents). The overall weight is obtained by multiplying the weight of the main criterion which each of the subcriteria. The definition of each of the criteria is provided in Additional file 3. NA not applicable, POC point-of-care. * The sum of columns may not add up to $100.0 \%$ due to rounding

value, which is the main criterion with the highest relative weight, the central laboratory test is slightly preferred over the POC test. This is mainly caused by the expected decrease in 'technical performance' and expected increase in 'risks' related to making management decision based on the POC test result (Table 2 and Additional file 3). These lower scores could not be offset by a slightly higher score on the subcriterion 'clinical utility' (i.e. $53.5 \%$ vs. $46.5 \%$ ), even though this is the subcriterion with the highest relative weight.

When considering the differences in preferences assigned to the 20 subcriteria for the POC and the central laboratory test (for both CRP and $\mathrm{HbA}_{1 \mathrm{c}}$ ), the main differences were found in the subcriteria 'clinical utility', the user's 'workload, its expected 'frequency of use', the extent to which the test is incorporated in current 'clinical guidelines', as well as its impact on 'overall costs'.

\section{Discussion}

The results indicate that the expert panel considered the main criterion 'clinical value' most important for comparing preferences for a POC test to its central laboratory equivalent (i.e. a relative weight of $51.8 \%$ ). In addition, its subcriterion 'clinical utility' was assigned the highest relative weight of all 20 subcriteria (i.e. 22.2\%).

When considering the overall outcome of the two case studies, POC CRP was preferred over its laboratory equivalent, whereas POC $\mathrm{HbA}_{1 \mathrm{c}}$ was not. Specifically, the POC CRP test was strongly preferred with regard to the subcriterion 'clinical utility', as opposed to $\mathrm{HbA}_{1 \mathrm{c}}$. This is in line with previous research, concluding that GPs prefer to have POC tests for rapidly diagnosing (or excluding) acute and/or serious conditions [11,32]. In addition, the POC CRP test may be used for multiple clinical indications [40], in contrast to $\mathrm{POC} \mathrm{HbA}_{1 \mathrm{c}}$ [41, 42]. Also, the 


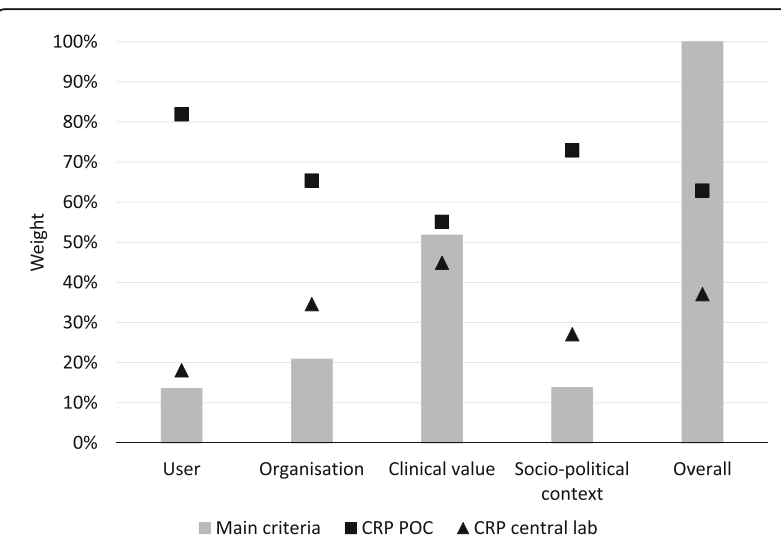

Fig. 3 Result of AHP analysis on the POC CRP test as compared to central laboratory testing. This figure shows the result of the analytical hierarchy process (AHP) analysis on the POC CRP test as compared to using the central laboratory test, on the four main criteria and the overall result, as well as the performance of the two tests on each criterion. The grey bars represent the relative weights of the four main criteria. The figure represents the performance of the POC test (square) and lab-test (triangle) on each criterion. $\mathrm{CRP}=\mathrm{C}$-reactive protein, $\mathrm{POC}=$ point-of-care

overall preference for POC CRP testing is in line with its current use (i.e. 80\% of Dutch GPs in 2015) [25]. In 2013, this percentage was however only $48 \%$ [11]. As the expert panel assigned a high preference for POC CRP with regard to the subcriterion 'clinical guidelines', the increased use of (POC) CRP testing is likely explained by its uptake in Dutch guidelines [43].

Furthermore, with regard to the subcriteria 'turn-around-time' and 'patient satisfaction', results indicate a strong preference for both POC CRP and POC $\mathrm{HbA}_{1 \mathrm{c}}$.

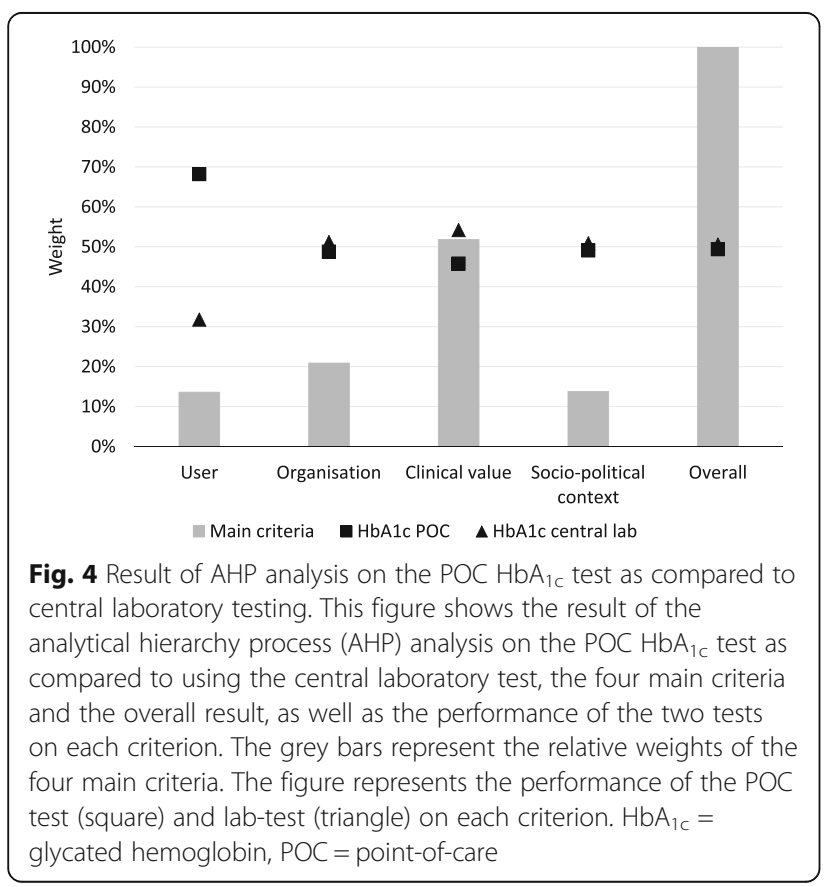

Similar findings have been reported in literature $[4,6]$. For POC $\mathrm{HbA}_{1 \mathrm{c}}$, these preferences are most likely attributable to the fact that this tests prevents an additional patient visit for a phlebotomy [26]. However, as the POC $\mathrm{HbA}_{1 \mathrm{c}}$ test is intended to be performed during the actual GP consultation, the experts assume that it will negatively affect the GP's 'workload'. In addition, previous research indicates that not all currently available devices meet the minimum performance requirements [44, 45], and cost-effectiveness analyses have been inconclusive $[27,46]$, which explains why this test is not considered of much added value in terms of 'technical performance' and the impact on 'overall costs'. This is in line with previous studies on POC testing (in general) [12,13].

Interestingly, results indicate that the expert panel considered the test's NPV to be far more important than its PPV (i.e. overall weight $7.1 \%$ vs. $1.5 \%$ ), independent of the type of test that was evaluated. This difference is most likely attributable to the strong gatekeeping function of GPs in the Netherlands. Consequently, diagnostic tests for use in primary care are primarily aimed at having a high NPV (to rule out a (serious) condition), instead of a high PPV (as is required for ruling in) [36].

\section{Strengths and limitations}

The main strength of the current study is that the set of criteria selected from literature were validated in interviews with a multidisciplinary team of 12 experts. This most likely contributed to preventing the AHP structure from becoming too complex by categorizing all aspects into a list of 20 subcriteria, while simultaneously ensuring that all relevant aspects remain incorporated.

As the GP is a key stakeholder in the decision to implement and use a POC test, a strength of this study is that three GPs participated both in the expert panel and the AHP session. As these GPs differed in the number of years working experience and/or had a different viewpoint on using POC tests, this likely resulted in a representative weighting of the criteria. However, this overrepresentation of GPs may have led to confirmation bias [47], as their current POC test use (i.e. one GP used POC $\mathrm{HbA}_{1 \mathrm{c}}$, whereas all three GPs used POC CRP) may have strengthened their preference towards POC CRP. When performing a separate analysis in which only the GPs' opinions were taken into account, it was indeed observed that the overall preference for a POC test increased from 62.9 to $69.9 \%$ for CRP, and from 49.4 to $51.2 \%$ for $\mathrm{HbA}_{1 \mathrm{c}}$ (Additional file 3: Table S3a). However, the overall conclusion was unaffected.

As the health insurer and the POC expert were not able to attend the group AHP session, they completed it individually afterwards. Both experts were provided with the scores (and explanations) given during the group session. Consequently, it cannot be ruled out that the scores of the other experts would have been affected if those two experts 
would have attended the group session. However, subgroup analyses revealed that the overall preference for a POC test was unaffected when the scores of these two experts were excluded from the analyses (i.e. $61.6 \%$ vs. $62.9 \%$ for POC CRP; $48.4 \%$ vs. $49.4 \%$ for POC $\mathrm{HbA}_{1 \mathrm{C}}$, as shown in Additional file 3: Table S3b).

In the current study, preference weights have been assigned to the four main criteria, as well as to the five subcriteria belonging to each of these four groups. The risk of such a clustered evaluation is that the weight of a subcriterion depends on the weight assigned to its main criterion. To illustrate this, the subcriterion 'clinical guidelines' was assigned a weight of $34.1 \%$, but as the main criterion it belongs to (i.e. 'socio-political context') was only assigned a weight of $13.8 \%$, the overall weight of 'clinical guidelines' is only $4.7 \%$. This may result in (slightly) underestimating the overall weight of some important criteria. The main benefit of this clustered evaluation, however, is that bias of overweighting main criteria is avoided, which would occur when weights of partially overlapping subcriteria were summed to calculate the weights of the main criteria.

\section{Recommendations}

Although the strong differences in both the degree of implementation as well as in the application of the CRP and the $\mathrm{HbA}_{1 \mathrm{c}}$ test likely enhance the generalizability of the study's results, future AHP sessions are recommended to find out whether this single set of criterion weights can reliably be applied to a wide variety of tests and settings.

Although the results of the current study indicate a preference for CRP testing on a POC analyzer, this cannot guarantee its (further) implementation and use in clinical practice. To make such a decision, additional (temporal) costs (and efforts) related to switching to a POC test should be considered. This for example includes costs related to the purchase and maintenance of the POC testing device, to obtaining the (blood) sample, as well as to educating the test's users. In addition, the results indicate that, besides costs, many other factors play a role in decisions regarding test implementation and use. As many of these factors cannot be captured in conventional cost-effectiveness analyses, it is important to obtain insight in stakeholders' experiences and preferences early on during the process of (POC) test development and its (eventual) implementation in clinical practice.

\section{Conclusion}

In conclusion, the list of criteria identified in the current study may facilitate efficient implementation and use of existing POC tests. In addition, it is likely valuable to predict the likelihood of implementation and use of
POC tests in early stages of development. The insights obtained in the barriers and facilitating factors of POC tests can be used to either predict the likelihood of implementation and use of POC tests in early stages of development, or to increase this probability, by allowing test developers to focus on the criteria that were considered most important.

\section{Additional files}

Additional file 1: Literature search. This file contains the extensive description of the literature search, which was used to identify criteria relevant for the analytical hierarchy process. (PDF $103 \mathrm{~kb}$ )

Additional file 2: Questions used for semi-structured interviews, and design of analytical hierarchy process session. This file contains an overview of the interview questions used for the semi-structured interviews, as well as an overview of the design of the analytical hierarchy process session. (PDF $291 \mathrm{~kb}$ )

Additional file 3: Results of interviews and analytical hierarchy process. This supplementary file contains an overview of the detailed results of the analysis of the analytical hierarchy process (AHP), including the weighting of the subcriteria, the group inconsistency and missing judgements during the analytical hierarchy process session, as well as the preferences regarding the subcriteria for the two alternatives (i.e. pointof-care (POC) C-reactive protein (CRP) vs. CRP in a central laboratory, as well as POC glycated haemoglobin ( $\mathrm{HbA1c}$ ) vs. $\mathrm{HbA} 1 \mathrm{c}$ in a central laboratory). (DOCX $73 \mathrm{~kb})$

\section{Abbreviations}

AHP: Analytic hierarchy process; CRP: C-reactive protein; GP: General practitioner; $\mathrm{HbA}_{1 c}$ : Glycated haemoglobin; MCDA: Multi-criteria decision analysis; POC: Point-of-care

\section{Acknowledgements}

We would like to thank all the experts who participated in the interviews and/or in the AHP session, as this study could not have been performed without their valuable input and expertise.

\section{Funding}

This study was not funded.

\section{Availability of data and materials}

The dataset supporting the conclusion of this article is included within the article and its additional files.

\section{Authors' contributions}

$M K, J H, E E, R K$ and MIJ were involved in the conception and design of the study. EE and MK performed the literature review. EE performed the expert interviews, and $\mathrm{EE}, \mathrm{MK}$ and $\mathrm{JH}$ coordinated the AHP session. $\mathrm{MK}, \mathrm{JH}$, and $\mathrm{EE}$ analyzed the data, and HK, MIJ, RK and RH contributed substantially to the interpretation of the results. MK drafted the manuscript, and $J \mathrm{H}, \mathrm{EE}, \mathrm{HK}, \mathrm{RH}$, MIJ and RK were major contributors in critically reviewing the manuscript. All authors read and approved the final manuscript.

\section{Ethics approval and consent to participate}

All participants gave verbal consent to participate and to, anonymously, record the interview and the expert panel session. The study did not subject participants to treatment or required participants to behave in a particular way, and it took place within the GCP guidelines. The study procedure was approved (file number BCE17690) by the BMS Ethics Committee, which is the Ethics Committee of the faculty of Behavioral, Management and Social Sciences of the University of Twente, Enschede, the Netherlands.

Consent for publication

Not applicable. 


\section{Competing interests}

The authors declare that they have no competing interests.

\section{Publisher's Note}

Springer Nature remains neutral with regard to jurisdictional claims in published maps and institutional affiliations.

\section{Author details}

'Department of Health Technology and Services Research, Faculty of Behavioural, Management and Social Sciences, Technical Medical Centre, University of Twente, P.O. Box 217, 7500, AE, Enschede, The Netherlands. ${ }^{2}$ Star-SHL diagnostic center, Etten-Leur, The Netherlands. ${ }^{3}$ Laboratory for Clinical Chemistry and Haematology, Jeroen Bosch Ziekenhuis, Den Bosch, The Netherlands.

Received: 13 November 2017 Accepted: 16 December 2018 Published online: 10 January 2019

\section{References}

1. Wiener JM, Tilly J. Population ageing in the United States of America: implications for public programmes. Int J Epidemiol. 2002;31:776-81.

2. Akhmetov I, Bubnov RV. Assessing value of innovative molecular diagnostic tests in the concept of predictive, preventive, and personalized medicine. EPMA J. 2015;6:19.

3. Hickner J, Thompson PJ, Wilkinson T, Epner P, Sheehan M, Pollock AM, Lee J, Duke CC, Jackson BR, Taylor JR. Primary care physicians' challenges in ordering clinical laboratory tests and interpreting results. J Am Board Fam Med. 2014:27:268-74.

4. Larsson A, Greig-Pylypczuk R, Huisman A. The state of point-of-care testing: a European perspective. Ups J Med Sci. 2015;120:1-10.

5. Price CP. Point of care testing. BMJ. 2001;322:1285-8.

6. Laurence CO, Gialamas A, Bubner T, Yelland L, Willson K, Ryan P, Beilby J. Point of care testing in general practice trial management $\mathrm{G}$ : patient satisfaction with point-of-care testing in general practice. Br J Gen Pract. 2010;60:e98-104

7. Gialamas A, Yelland LN, Ryan P, Willson K, Laurence CO, Bubner TK, Tideman $\mathrm{P}$, Beilby JJ. Does point-of-care testing lead to the same or better adherence to medication? A randomised controlled trial: the PoCT in general practice trial. Med J Aust. 2009;191:487-91.

8. Bubner TK, Laurence CO, Gialamas A, Yelland LN, Ryan P, Willson KJ Tideman P, Worley P, Beilby JJ. Effectiveness of point-of-care testing for therapeutic control of chronic conditions: results from the PoCT in general practice trial. Med J Aust. 2009:190:624-6.

9. National Institute of Biomedical Imaging and Bioengineering/National Heart Lung Blood Institute/National Science Foundation Workshop Faculty, Price $C P$, Kricka LJ. improving healthcare accessibility through point-of-care technologies. Clin Chem. 2007:53:1665-75.

10. Cals JW, Butler CC, Hopstaken RM, Hood K, Dinant GJ. Effect of point of care testing for $C$ reactive protein and training in communication skills on antibiotic use in lower respiratory tract infections: cluster randomised trial. BMJ. 2009:338:b1374.

11. Howick J, Cals JW, Jones C, Price CP, Pluddemann A, Heneghan C, Berger MY, Buntinx F, Hickner J, Pace W, et al. Current and future use of point-ofcare tests in primary care: an international survey in Australia, Belgium, the Netherlands, the UK and the USA. BMJ Open. 2014;4:e005611.

12. Jones $\mathrm{CH}$, Howick J, Roberts NW, Price CP, Heneghan C, Pluddemann A Thompson M. Primary care clinicians' attitudes towards point-of-care blood testing: a systematic review of qualitative studies. BMC Fam Pract. 2013:14:117.

13. Lewandrowski K, Gregory K, Macmillan D. Assuring quality in point-of-care testing: evolution of technologies, informatics, and program management. Arch Pathol Lab Med. 2011;135:1405-14.

14. Greenhalgh T, Robert G, Macfarlane F, Bate P, Kyriakidou O. Diffusion of innovations in service organizations: systematic review and recommendations. Milbank Q. 2004;82:581-629.

15. Grol $R$, Wensing $M$, Eccles $M$, Davis $D$. Improving patient care: the implementation of change in health care, second edition: John Wiley \& Sons Ltd; 2013.

16. Thokala P, Devlin N, Marsh K, Baltussen R, Boysen M, Kalo Z, Longrenn $T$, Mussen F, Peacock S. Watkins J, ljzerman M Multiple criteria decision analysis for health care decision making--an introduction: report 1 of the ISPOR MCDA emerging good practices task force. Value Health. 2016:19:1-13.

17. Saaty TL. The analytic hierarchy process: planning, priority setting, resource allocation. New York: McGraw-Hill; 1980.

18. Hummel JM, Bridges JF, MJ IJ. Group decision making with the analytic hierarchy process in benefit-risk assessment: a tutorial. Patient. 2014;7:129-40.

19. Saaty TL. Relative measurement and its generalization in decision making: why pairwise comparisons are central in mathematics for the measurement of intangible factors. The analytic hierarchy/network process. Rev R Acad Cien Serie A Mat. 2008;102:251-318.

20. Minnaard MC, van de Pol AC, Hopstaken RM, van Delft S, Broekhuizen BD, Verheij TJ, de Wit NJ. C-reactive protein point-of-care testing and associated antibiotic prescribing. Fam Pract. 2016;33:408-13.

21. Cals JW, Schot MJ, de Jong SA, Dinant GJ, Hopstaken RM. Point-of-care Creactive protein testing and antibiotic prescribing for respiratory tract infections: a randomized controlled trial. Ann Fam Med. 2010;8:124-33.

22. Huang $Y$, Chen $R$, Wu T, Wei $X$, Guo A. Association between point-of-care CRP testing and antibiotic prescribing in respiratory tract infections: a systematic review and meta-analysis of primary care studies. Br J Gen Pract. 2013;63:e787-94.

23. Aabenhus R, Jensen JU, Jorgensen KJ, Hrobjartsson A, Bjerrum L. Biomarkers as point-of-care tests to guide prescription of antibiotics in patients with acute respiratory infections in primary care. Cochrane Database Syst Rev. 2014:27:CD010130.

24. Tonkin-Crine SK, Tan PS, van Hecke O, Wang K, Roberts NW, McCullough A, Hansen MP, Butler CC, Del Mar CB: Clinician-targeted interventions to influence antibiotic prescribing behaviour for acute respiratory infections in primary care: an overview of systematic reviews. Cochrane Database Syst Rev 2017, 9:CD012252.

25. Kip MMA, Noltes AM, Koffijberg H, MJ IJ, Kusters R. Improving early exclusion of acute coronary syndrome in primary care: the added value of point-of-care troponin as stated by general practitioners. Prim Health Care Res Dev. 2017:1-12.

26. Pluddemann A, Price CP, Thompson M, Wolstenholme J, Heneghan C. Primary care diagnostic technology update: point-of-care testing for glycosylated haemoglobin. Br J Gen Pract. 2011;61:139-40.

27. Grieve R, Beech R, Vincent J, Mazurkiewicz J. Near patient testing in diabetes clinics: appraising the costs and outcomes. Health Technol Assess. 1999:3:1-74

28. Marsh K, IJ M, Thokala P, Baltussen R, Boysen M, Kalo Z, Lonngren T, Mussen F, Peacock S, Watkins J, et al. Multiple criteria decision analysis for health care decision making--emerging good practices: report 2 of the ISPOR MCDA emerging good practices task force. Value Health. 2016;19:125-37.

29. Kleinveld HA, Raijmakers MTM, Vermeer HJ, Oosterhuis WP. Visiedocument NVKC Point-of-care testen in de eerste lijn, Heerlen. 2012;8:1-8.

30. Briggs C, Kimber S, Green L. Where are we at with point-of-care testing in haematology? Br J Haematol. 2012;158:679-90.

31. Hofland HJ. Point of care testing and selftest related consultations in general practices in the Netherlands: an exploratory study on general practitioners' experiences. Enschede: University of Twente. 2010:30.

32. Cals J, van Weert H. Point-of-care tests in general practice: hope or hype? Eur J Gen Pract. 2013;19:251-6.

33. Jackman J, Uy M, Hsieh YH, Rompalo A, Hogan T, Huppert J, Jett-Goheen M, Gaydos C. Minding the gap: An approach to determine critical drivers in the development of Point of Care diagnostics. Point Care. 2012;11:130-9.

34. de Vries C, Doggen C, Hilbers E, Verheij R, IJ M, Geertsma R, Kusters R. Results of a survey among GP practices on how they manage patient safety aspects related to point-of-care testing in every day practice. BMC Fam Pract. 2015;16:9.

35. Heneghan C, Van den Bruel A, Thompson M, Price C, Wilson P, Crabb N Deeks JJ, Williams D-A. Diagnostics forum 2013 report: fast-tracking the evidence for implementing diagnostic tests. Pp. 16. Oxford: University of Oxford; 2013. p. 16.

36. Hopstaken RM, Kleinveld HA, van Balen JAM, Krabbe JG, Van den Broek S, Weel J, Slingerland RJ, Ruiter C, Kusters GCM: Richtlijn: Point of care testing (POCT) in de huisartsenzorg. 2015.

37. TNO innovation for life. MIDI: Meetinstrument Determinanten van Innovaties. Leiden; 2012. p. 4

38. Hummel JM, van Rossum W, Verkerke GJ, Rakhorst G. The effects of team expert choice on group-decision making in collaborative new product development: a pilot study. J Multi-Criteria Decis Anal. 2000;9(1-3). 
39. Hilgerink MP, Hummel MJ, Manohar S, Vaartjes SR, ljzerman MJ. Assessment of the added value of the Twente photoacoustic Mammoscope in breast cancer diagnosis. Med Devices (Auckl). 2011;4:107-15.

40. Verbakel JY, Lemiengre MB, De Burghgraeve T, De Sutter A, Aertgeerts B, Shinkins B, Perera R, Mant D, Van den Bruel A, Buntinx F. Should all acutely ill children in primary care be tested with point-of-care CRP: a cluster randomised trial. BMC Med. 2016;14:131.

41. Jia W. Standardising HbA1c-based diabetes diagnosis: opportunities and challenges. Expert Rev Mol Diagn. 2016;16:343-55.

42. World Health Organization. Use of glycated haemoglobin (HbA1c) in the diagnosis of diabetes mellitus. Geneva: Abbreviated report of a WHO consultation; 2011. p. 25.

43. Verlee L, Verheij TJ, Hopstaken RM, Prins JM, Salome PL, Bindels PJ. summary of NHG practice guideline 'Acute cough'. Ned Tijdschr Geneeskd. 2012;156:A4188

44. Lenters-Westra E, Slingerland RJ. Three of 7 hemoglobin A1c point-of-care instruments do not meet generally accepted analytical performance criteria. Clin Chem. 2014;60:1062-72.

45. Lenters-Westra E, Slingerland RJ. Six of eight hemoglobin A1c point-of-care instruments do not meet the general accepted analytical performance criteria. Clin Chem. 2010;56:44-52.

46. Khunti K, Stone MA, Burden AC, Turner D, Raymond NT, Burden M, Baker R. Randomised controlled trial of near-patient testing for glycated haemoglobin in people with type 2 diabetes mellitus. Br J Gen Pract. 2006; 56:511-7.

47. Glick M. Believing is seeing: confirmation bias. J Am Dent Assoc. 2017;148: $131-2$.

Ready to submit your research? Choose BMC and benefit from:

- fast, convenient online submission

- thorough peer review by experienced researchers in your field

- rapid publication on acceptance

- support for research data, including large and complex data types

- gold Open Access which fosters wider collaboration and increased citations

- maximum visibility for your research: over $100 \mathrm{M}$ website views per year

At $\mathrm{BMC}$, research is always in progress.

Learn more biomedcentral.com/submissions 